\title{
Lo clásico en el siglo XVIII: cuestión de conciencia de clase
}

\author{
Luis UnCeta Gómez
}

Universidad Autónoma de Madrid

CES.XVIII, núm. 22 (2012), págs. 141-164. 


\section{RESUMEN}

Este trabajo aborda el empleo del elemento clásico en la obra poética de tres autores líricos del siglo XVIII español poco conocidos: el conde de Noroña, José de Vargas y Ponce y José María Vaca de Guzmán y Manrique. Todos ellos comparten un amplio conocimiento de la Antigüedad grecorromana y, además, todos ellos, de acuerdo con la actitud de su época hacia la herencia clásica, hacen un uso ilustrado de la herencia clásica, con un evidente afán ideológico y elitista, por encima del interés estrictamente estético o artístico.

Palabras clave

Poesía lírica, siglo XVIII, tradición clásica.

\section{AbSTRACT}

This paper deals with use of the classical element in the poetic works of three scarcely known Spanish lyrical poets who composed their works in the $18^{\text {th }}$ century: the Count of Noroña, José de Vargas y Ponce, and José María Vaca de Guzmán y Manrique. The three of them share an accurate knowledge of the Greco-Roman Antiquity, and, in addition, all of them, according to the attitude of their time towards the classical heritage, make use of the Classical Tradition in an illustrated way, with an ideological and elitist aim, rather than with an esthetic or an artistic one.

KEYWORDS

Lyrical poetry, $18^{\text {th }}$ century, classical tradition.

Recibido: 12-12-2011. Aceptado: 02-03-2012. 


\section{Introducción}

A pesar de los denuestos que, desde la época romántica, ha recibido tradicionalmente la literatura ilustrada en general y, muy en particular, la poesía del siglo XVIII — un periodo con marcada predilección por la prosa—, de un tiempo a esta parte está siendo reivindicada en los estudios literarios, no tanto por sus virtudes artísticas, sino más bien en atención a los propios ideales que sobre la figura y las funciones del poeta estuvieron vigentes en esa época (cf. Reyes, 2006 ${ }^{4}: 17$ y ss.). La complejidad y multiplicidad de matices de la literatura creada en este momento ${ }^{1}$ dificultan además la filiación de artistas muy dispares a un movimiento unitario, supuestamente ramplón y falto de originalidad. Esto es así, es evidente, si se compara con el momento áureo precedente, pero es necesario precaverse contra los tópicos e ideas preconcebidas habituales, y otorgar a a esta época la importancia justa que le corresponda.

Cualquier manual o introducción advierte sobre los peligros terminológicos que encierra el aplicar la denominación Neoclasicismo a unos límites temporales difusos, sujetos a periodizaciones diversas y a unos criterios estéticos y artísticos mal definidos. En los últimos tiempos, R. P. Sebold ${ }^{2}$, estudioso de la época e influyente crítico, ha tratado de definir el Neoclasicismo como «nuevo clasicismo español» — el volver la vista al horizonte grecolatino es un ideal estético presente en la literatura europea, al menos, desde el Humanismo renacentista—, y le ha atribuido los siguientes rasgos caracterizadores:

1) géneros poéticos antiguos, para cuya adaptación a la literatura española ya se habían formulado procedimientos durante el Renacimiento;

2) modelos cultos nacionales;

3) modelos populares nacionales (metros y estrofas de tradición netamente española que nunca fueron despreciados por los neoclásicos);

4) modelos extranjeros compatibles con la tradición española.

1 Según advierte Carnero, «pasado el momento gongorino, la poesía del XVIII se diversifica en una abanico de tendencias que no se excluyen ni se sustituyen sucesivamente; se encabalgan y tienen vigencia simultánea, de modo que la inmensa mayoría de los poetas de la segunda mitad del siglo militan en varias de ellas o en todas, teniéndolas en su horizonte creativo como posibilidades alternativas» (CARNER0, 1995, I: LII).

2 En Carnero (1995, I: 151). 
Durante este periodo, pues, lo frecuente es que el elemento de ascendencia grecolatina provenga de la propia tradición española, que ya lo había empleado en muchos puntos de su historia. Cervantes, fray Luis o Garcilaso ofrecían un ideal áureo que permitía una renovación de la literatura sin acudir necesariamente a autores más antiguos ${ }^{3}$. Sin embargo, según nos disponemos a ver, los autores en los que se fija este trabajo están profundamente versados en los saberes de la Antigüedad clásica. De acuerdo con el ideal ilustrado que representan, todos ellos son, además, profesionales con ocupaciones corrientes que, no obstante, cultivaron la creación literaria con ardor y pusieron su pluma al servicio de la sociedad. La poesía — comenta J. Polt (1975: 19)— resultaba

[...] una actividad entre muchas, perfectamente compatible con la carrera de las armas o de la administración pública. El tipo de artista extrasocial y antisocial no solía darse en el siglo xvIII, última época que conservara un ideal polifacético del hombre. Entonces un poeta no se creía menos poeta por elaborar informes sobre minas de carbón, ni un soldado menos soldado por escribir versos.

No en vano, durante este período, la creación artística y literaria quedaba en manos de unos pocos que, directamente o por medio del mecenazgo, estaban capacitados para contribuir a la potenciación y difusión de la cultura. De hecho, salvo clérigos, militares, dirigentes o funcionarios, el grueso de la población ni siquiera sabía leer ni escribir ${ }^{4}$, «en un siglo de bajísima escolarización, misoneísta y en el que las relaciones de las clases sociales son herméticas, con unas funciones asignadas de antemano» (Fortuño, 1997: 19).

Así las cosas, en lo que sigue indagaremos en el uso que hacen de las fuentes clásicas tres autores líricos de este período, para intentar determinar las funciones que el ideal ilustrado atribuye a la tradición grecolatina. En todos los casos, nos encontraremos ante poetas poco conocidos y con escaso reconocimiento de la crítica; sin embargo, esa parca relevancia literaria permitirá realizar otro tipo de consideraciones acerca del alcance de su obra, por ser representativos de una clase y un ideal.

3 Cf. Reyes (2006": 25): «La anacreóntica de Villegas, la égloga garcilasiana, el tema del retiro luisiano o la oda heroica de Herrera, en lo que tienen de herencia rediviva, son otros tantos testimonios de cómo la renovación poética del XVIII español no se hace en pugna con un pasado literario, sino en clara dependencia de él».

4 Véase «La educación en la España del siglo XVIII», a cargo de F. López, en Carnero (1995: 4 y ss.). 
Aunque conocido sobre todo por sus traducciones de Poesías asiáticas ${ }^{5}$, el conde de Noroña es un autor de enorme producción poética — enorme a pesar de ser militar de profesión y de haber vivido unos cincuenta años-, que se erige con su obra en representante de las tres tendencias fundamentales de la poesía de su siglo: ilustrada, anacreóntica y prerromántica. De Cueto nos proporciona el siguiente semblante biográfico de este personaje:

Nació en la villa de Castellón de la Plana el 6 de mayo de 1760. En el año de 1766 fue nombrado caballero paje del Rey; en 1778 capitán de dragones del regimiento de Lusitania. Se distinguió notablemente en el sitio de Gibraltar, y estuvo a pique de perder la vida en el navío Paula, que se colocó en primera fila en el combate llamado de los empalletados. Hecha la paz con Inglaterra, le nombró el Rey su enviado extraordinario y ministro plenipotenciario en la corte de San Petersburgo. En 1792, época de la guerra de España con la República francesa, volvió al servicio de las armas. Dotado de excelentes prendas militares, llegó al alto grado de teniente general, y, como tal, mandó una parte del ejército español en Galicia durante la guerra de la Independencia. Alcanzó sobre los franceses la victoria del puente de San Payo. Murió el conde de Noroña en Madrid, a principios del año de 1815. Las tareas militares y diplomáticas no apartaron nunca al conde del cultivo de las letras, que eran su principal recreo (De Cueto, 1952, II: 426).

Las contradicciones de su siglo encuentran reflejo en su poesía, «en la que se alternan variedad de temas: míticos e históricos, metafísicos y realistas, reflexivos y de chanza y humor, condenatorios y elogiosos, trascendentales y de circunstancias, moralizantes y hedonistas» (Fortuño, 1997: 28). Es cosa sabida, además, que las reminiscencias grecolatinas son un lugar común de la época. Pero en Noroña, profundamente instruido en las letras clásicas, ésta es una característica aún más acusada, si cabe. Basten como ejemplo algunos de los versos iniciales de «A la abertura de una sociedad de amigos para aprehender la historia de España en Jerez de la Frontera», oda en estancias:

¡Ay! Si Apolo me hubiera / la cítara lesbia concedido / y en el pecho sintiera / hervir con llama ardiente / el pítico furor, jcuán atrevido / con descubierta frente / mi débil voz alzara / para que en ambos polos resonara! / Y, esforzando el acento, / el eco hasta el Olimpo llegaría. / Dejara el sacro asiento / por escuchar mis sones

\footnotetext{
5 Editadas por S. ForTuño (2003).
} 
/ el coro de los dioses y de alegría / bañadas sus mansiones, / y todos admirados / de versos de un mortal al Cielo alzados (vv. 1-16).

Caben pocas alusiones más en unos versos en los que el mundo clásico despliega toda su grandeza y en los que, junto al abuso de las alusiones mitológicas, no faltan ni el empleo de topónimos clásicos («Asta Regia» [v. 50], por Jerez de la Frontera), ni el recuerdo de citas célebres («Echada está la suerte...» [v. 142]), entre otros recursos alusivos.

La aparición de motivos y modos compositivos de clara estirpe clásica es igualmente abundante en «A la paz entre España y Francia», una de sus composiciones que más elogios de la crítica ha recibido. Se trata, como explica Fortuño (1997: 144), de «una extensa oda en forma alegórica, con un tono altamente épico, en estrofas aliteradas de abundante empleo en el Neoclasicismo». Sus primeros versos dan nuevamente idea de lo que será el tono de la composición:

La Discordia levanta su cabeza, / de víboras crinada, / las mueve, las sacude y agitada / retiembla la mansión de la tristeza. / La turbia Estigia crece, / el tenebroso Averno se estremece (vv. 1-6).

Ésta resulta la tónica de la poesía de alguien que a cada paso hace gala de sus conocimientos clásicos y los emplea a modo de emblemas culturalistas, con intención de embellecer sus composiciones. No en vano, quizá no entre las mejores, pero sin duda de las más sentidas, es la que dedica «A la buena memoria de Don Antonio Berdejo, canónigo de Tarragona», quien fuera su maestro de letras clásicas:

Una voz resonante, / que en la mansión etérea penetrara, / y a Júpiter Tonante / el rayo de la diestra derribara, / Antonio, deseara / para librar tu nombre esclarecido / del Tiempo avaro y del oscuro olvido (vv. 1-6).

La oda se concibe como una alegoría en la que el duro ascenso a la cumbre en la que se encuentra el templo del dios Apolo representa el arduo aprendizaje de las lenguas griega y latina:

Y a la falda del Pindo me llevaste. / De su escabrosa altura / absorto, volví atrás el pie dudoso. / Pero tú, con dulzura / serenando mi pecho congojoso, / me dijiste animoso: / «Quien no se afana en el combate ardiente, / nunca de lauro ceñirá su frente» (vv. 14-21). 
Y le sirve, en la línea de lo que hace Marco Aurelio en sus Meditaciones, como reconocimiento al maestro que le enseñó a amar a los clásicos y le empujó al cultivo de las letras: «Tú al venerable Homero / me diste a conocer» [...] (vv. 49-50); «Conocía al grave Horacio, / dulce Ovidio, Virgilio altisonoro, / y a cuantos en el Lacio / amaba Febo y el castalio coro» (vv. 56-59).

Este continuo recurrir a las fuentes clásicas da a su poesía cierta afectación artificial y, en muchas ocasiones, puede resultar un recurso frío y estéril. Pero no hay duda de que constituye uno de los rasgos más característicos de su obra. Es frecuente la recreación de un tópico clásico como disculpa para una composición. El desarrollo del motivo del passer, deliciae meae puellae catuliano ${ }^{6}$ funciona como leitmotiv para los versos de «A una paloma»:

Dulce paloma mía, / vuela, vuela al momento, / y, buscando a mi Amira, / colócate en su pecho. [...] Si duerme, te suplico / que le guardes el sueño, / la cubras con tus alas, / y defiendas de Febo (vv. 1-4; 17-20).

Y reaparece en «A un pajarillo»:

¡Oh tierno pajarillo!, / no tengas, no, cuidado / ni tampoco te asustes / por verte entre sus manos [...]. Si acaso me soltara / iría revolando / en torno de su pecho, donde haría descanso (vv. 1-4; 17-20).

Y es que Catulo constituye un excelente modelo para la poesía anacreóntica, aquella, tan en boga en la época y tan del gusto del autor, que canta el amor, el vino, el baile y la belleza femenina, en versos ligeros, llenos de sensualidad y plagados también de alusiones mitológicas (cf. Fortuño, 1997: 39). Vale la pena reproducir las palabras que Reyes dedica a este tipo de composiciones:

La anacreóntica es, en efecto, el género central de esta nueva sensibilidad [Rococó], aunque había sido ya muy cultivada en la España de los Siglos de Oro, siguiendo la tradición clásica y desde luego con otro tono. A esa revitalización que

${ }^{6}$ Era costumbre romana que las damas tuvieran pájaros domesticados, regalo usual de sus amantes. El poema II del corpus de Catulo dice así: Passer, deliciae meae puellae, / quicum ludere, quem in sinu tenere, / quoi primum digitum dare adpetenti / et acris solet incitare morsus, / cum desiderio meo nitenti / carum nescio quid lubet iocari / et solaciolum sui doloris, / credo, ut tum grauis acquiescat ardor; / tecum ludere sicut ipsa possem / et tristis animi leuare cura. «Pájaro, delicias de mi amada, con quien ella se complace en jugar, a quien tiene en su regazo, a quien ofrece, al pedírselo, la punta del dedo, provocando agudos mordiscos, cuando mi radiante amor gusta de entregarse a no sé qué agradables solaces que alivien un tanto su tortura, a fin de calmar, sin duda, mi rigurosa pasión: ojalá pudiera, como ella, jugar contigo y disipar las tristes cuitas de mi corazón» (trad. M. Dolç, Alma Mater). 
el sensualismo ilustrado hace de los placeres anacreónticos hay que atribuir el éxito que conoce en el XVIII un poeta áureo como Villegas. Ese sensualismo guarda también relación con el gusto dieciochesco por los temas pastoriles [...] (Reyes, $2006^{4}: 39$ ).

Excelente ejemplo de ello es también el poema «A mi criado»:

Debajo de este mirto / pon la mesa, muchacho [...]. Llamarás al convite / no criticones sabios / no viejos que regañan, / no ricos que son raros, / sino niñas bonitas, / muchachos agraciados [...]. Formaremos un baile / con repetidos saltos / del modo que lo hacía / Anacreonte anciano (vv. 1-2; 5-10; 17-20).

Este marco idílico sirve de excusa perfecta para la recreación de un famoso motivo clásico, en la exaltación de la vida y el amor ${ }^{7}$, que en la voz del conde suena así:

A mi Lisis daréla / un beso, dos, tres, cuatro, / veinte, cuarenta, ciento, / un millón y otros tantos, / de modo que se queden / confusos y admirados / aquellos que pretendan / ya verlos ya contarlos (vv. 25-32) ${ }^{8}$.

Según vemos, además, el poeta se complace tomando prestados otros procedimientos de la poesía elegíaca, como es la atribución de un nombre ficticio para su amada. Desfilan así por sus versos Amira y Lisis (que ya han aparecido), o Silvia, Nerina y Belisa. Sus modelos son claros: «[...] las musas latinas / que el amor celebraron / de Lesbia, Delia y Cintia ${ }^{9} »$. Por antonomasia, Lesbia se convertirá incluso en sinónimo de amada («[...] mi Lesbia hermosa», en «Dichas soñadas», v. 65); y el propio conde se servirá de un pseudónimo poético (Feniso, en «A Venus», v. 17).

Otra referencia continua a un tema clásico, con un modelo que se reconoce al instante, es el rechazo de la guerra que Tibulo desarrollara en su poema I 10. Es profundo y acérrimo el antibelicismo del conde — nadie mejor para hablar de los horrores de la guerra que un militar-, para quien, según su propia expresión, «la trompa y la lira [...] saben sonar de acuerdo» («De mí mismo», vv. 35-36).

7 Nos referimos a los famosos versos catulianos: «Dame mil besos, luego ciento, luego otros mil, luego cien más, luego otros mil todavía, luego ciento. Después, cuando hayamos sumado muchos miles, embrollaremos la cuenta para no saberla o para que ningún envidioso pueda aojarnos cuando sepa que fueron tantos nuestros besos» (Catulo, V, 7-13).

8 Cf. también: «Voy a dar a mi Lisis / mil besos, mil abrazos» («Chasco cruel», vv. 17-18).

9 Nombres que Catulo, Tibulo y Propercio, respectivamente, dan a sus amadas en sus composiciones. La cita está tomada del poema «Al lector», vv. 18-20; véase también «Excelencia de Lisis». 
Sin embargo, a pesar de su condición de militar, el amor es su gran tema, y la diosa Venus asoma impúdica en buena parte de sus composiciones (cf. «A Venus», «A Cupido»). El ataque frontal a la guerra y la invitación al goce sensorial son patentes en poemas como el dedicado «A Don Francisco Javier Venegas de Saavedra»:

Venegas, ¿de qué sirve con afanes / seguir a Marte fiero, / ver ondear al céfiro ligero / del monarca español los tafetanes, / relumbrar los fusiles / y arder los campeones como Aquiles? ${ }^{10}[\ldots]$ ¿Por un aplauso vano o por la fama, / cosas todas de viento, / hemos de abandonar aquel contento / y aquellos dulces gustos que derrama / sobre nuestras cabezas / la Diosa tutelar de las bellezas? / No, Venegas. Mi Amira y tu Belisa / con semblante halagüeño / nos convidan a huir tan fiero ceño, / y a buscar con ardor su dulce risa, / que en sus labios hermosos / hallaremos combates más graciosos (vv. 1-6; 19-30).

Los ecos del mencionado poema de Tibulo, consistentes en la exaltación de la paz, se dejarán notar en otras muchas ocasiones: «Imprecación contra la guerra (A Don Fernando Cagigal)», la ya mencionada «A la paz entre España y Francia» o la segunda composición dedicada «A Don Francisco Javier Venegas de Saavedra, por la paz de 20 de enero de 1783», entre otras.

Las referencias a tópicos clásicos ${ }^{11}$ no escapan ni siquiera a la vena cómica, muy desarrollada también en este autor. En las dos «Odas al Coronel del regimiento de la Posma ${ }^{12} »$, cuyo título da ya idea de su espíritu burlón, el poeta aborda contrafacturas de tópicos muy recurrentes como beatus ille, aurea mediocritas o tempus fugit, incluso con apropiación de versos completos. Desde los primeros,

${ }^{10}$ Estos seis primeros versos podrían encontrar su inspiración en el neque excitatur classico miles truci (Hor. ep. II 5), según R. Navarro Durán (ápud ForTuño, 1997: 122, nota).

11 Para la exhortación al carpe diem horaciano y el collige, uirgo, rosas de Ausonio, véanse, por ejemplo, los poemas «A Drusila» 0 «A una muchacha»: «Sigue, sigue cogiendo, / ya que te hallas despierta, / las flores que te ofrece / tu dulce primavera, / ahora que en tu rostro / están puras y frescas, / y tus ojos despiden / vivísimas centellas. [...] Porque si retardas / y el cano tiempo llega, / deshará con un soplo / las gracias que desprecias» (vv. 13-20; 29-32). Un buen ejemplo de locus amoenus puede verse en «Dichas soñadas».

12 «Persona lenta y pesada en su modo de obrar» (DRAE). Al respecto, De CuETo (1952, II: 443, nota) nos proporciona la siguiente información: «El Marqués de Méritos, para ridiculizar a la gente apática y cachazuda, se inventó el imaginario empleo de Coronel del Regimiento de Posma, que se aplicaba a sí mismo. Esta creación fantástica de su carácter chancero alcanzó un éxito extremado y tuvo eco y aplauso en la sociedad más culta y hasta en el palacio de los reyes. "Trovadores del mejor numen, dice un biógrafo, cantaron en loor del Cuerpo Posmático. El Conde de Ureña compuso, con este motivo, el gracioso poema La Posmodia. El Conde de Noroña dedicó al Coronel dos odas, arregladas a las ordenanzas que el jefe le había dado"». Véase, además, un análisis de las mismas en ForTUÑo (1997: 61-65). 
¡Feliz aquel, que lejos de los cuidados, / y pleitos enfadosos, / aborrece los ecos horrorosos / de la trompa, que anima a los soldados, / y con sencillo pecho / nunca quisiera moverse de su lecho! (vv. 1-6),

resuenan todavía con fuerza los que compusiera Horacio ${ }^{13}$, a la vez que entroncan con nuestra propia tradición literaria ${ }^{14}$.

En esta misma línea, hemos de mencionar La Quicaida, poema épico burlesco con más de 3.300 versos repartidos en ocho cantos, en el que, por medio de un estilo grandilocuente y ampuloso, se relatan los esfuerzos de la protagonista, la joven Quica, para recuperar la flor con la que acapara la atención de los mozos, que le ha sido arrebatada por Tirsa, su antagonista. La causa de la hilaridad es obvia, al encontrarse ambos elementos, y el autor es plenamente consciente de ello («En tono grave canto frioleras», v. 6). Y se empeñará en usar y abusar de referencias mitológicas o alusiones intertextuales. El remedo humorístico de las grandes epopeyas es en ocasiones fácil. En el exordio paródico del canto I, las huellas son claras (invocación a la Musa, empleo del epíteto épico, incluso el primer verso de la Eneida —Arma uirumque cano-):

Canto el enojo y el cruel despecho, / que produjo una rosa de cien hojas / en el sensible pecho / de la graciosa Quica; sus congojas, / y sus guerras y su triunfo [...]. Oh Musa, que a los pechos aquejados / pones delante la agradable risa, / y lanzas al Averno a toda prisa / los negros melancólicos cuidados, / mi tibio pecho inflama, / y en mi labio derrama / con abundancia tantos gracejos, / que se estiren los tristes sobrecejos / al escuchar mi canto (canto I, vv. 1-15).

Igualmente frecuentes son la refacción de géneros clásicos — hemos hablado de la épica, pero también cultivó la égloga («Nise») o el epinicio («A la batalla de Trullas») — o la paráfrasis de versos completos. En ocasiones de manera algo velada, a las claras otras veces. Este último es el caso de un poema cuya deuda expresa desde el título: «Imitando la Oda XII del libro I de Horacio: uitas hinnuleo». Se equivoca el autor con la referencia (en realidad está imitando la oda XXIII), pero amplifica con gracia el motivo. Dejemos hablar al predecesor y a su émulo:

13 «Feliz aquel que, sin negocio alguno, como los hombres de antaño los campos paternos con su yunta labra libre de usura, al que nunca despierta en las filas clarín truculento, quien no teme al mar airado y el foro rehuye y umbrales soberbios de los ciudadanos ricos» (vv. 1-8; trad. V. Cristóbal, Cátedra)

14 «La influencia de fray Luis de León, destacada en la poesía dieciochesca, se aprecia en el conde Noroña en el uso de la métrica (lira) y en su convención poética (oda), que pone una vez más de manifiesto el sustrato clásico de esta poesía» (ForTuño, 1997: 61). Para un estudio del tópico en algunos de sus más insignes cultivadores en lengua castellana, véase Picón (2005). 
Me andas, Cloe, evitando como el cervatillo que a su temerosa madre en extraviados montes busca y con vano miedo al bosque y a las brisas. Si la primavera llega movedizas frondas agitando, si el verde lagarto se mueve entre las zarzas, tiemblan tus rodillas y ánimo. Mas ni fiero tigre ni gétulo león soy que te destroce: no sigas corriendo tras tu madre, que estás en sazón ya para el hombre (Horacio, Odas I 23; trad. V. Cristóbal, Cátedra).

Cual corcillo temeroso, / que siempre a su madre unido, / nunca sin ella ha sabido / dar un paso con reposo, / si se aparta, presuroso / la va a buscar al momento, / trepa los montes y, atento / a cuanto bulle, se espanta, / ya se agite alguna planta, / ya en las hojas silbe el viento. [...] No soy lobo carnicero, / hambriento de pasto humano, / que despedazarte quiero. [...] Ya aquel tiempo, que inocente / debieras amar su lado, / cual relámpago ha pasado. / Y ya aparece en tu frente / el resplandor que patente / hace la edad del amor (vv. 1-10; 21-24; 31-36).

Con el tiempo el conde irá evolucionando en sus modos compositivos y se irá despojando paulatinamente del ropaje neoclásico, para adentrarse en lo que se suele conocer con el nombre de prerromanticismo. Los motivos, las citas y los tópicos de la Antigüedad irán dejando paso a elementos de cuño más claramente romántico, como la melancolía del alma o los parajes lúgubres y oscuros. El amor no será ya un niño alado, sino un ser mucho más aterrador:

Este es Amor, un monstruo formidable / de aspecto torvo, de maldad espejo, / con cien ojos y lenguas otras tantas, / armado de furor, todo veneno («La noche triste», vv. 45-48).

Pero ni aun así podrá evitar que se cuelen alusiones mitológicas — «el hilo que llevó Teseo» (ibídem, v. 236), por ejemplo— o elementos luminosos propios de su poesía anterior — «claror febeo» (ibídem, v. 16).

\section{José de Vargas y Ponce}

De Cueto nos proporciona un breve perfil biográfico de este erudito, paradigma de hombre ilustrado — aunque a caballo con el programa liberal—, al que también le tocó vivir un momento convulso de la historia de España:

Nació en Cádiz, de ilustre familia, el 10 de junio de 1760, y siguió con fruto desde su primera juventud la carrera de la marina militar. Pero las letras absorbieron muy luego la mayor parte de su atención y de sus tareas. Siendo todavía guar- 
dia-marina, escribió un Elogio de Alfonso el Sabio, que fue premiado por la Real Academia Española. Diputado en las Cortes de 1813 y 1814, apoyó activamente el sistema político inaugurado con el célebre código constitutivo promulgado en 1812. Esta circunstancia le obligó a vivir oscurecido desde el momento en que fue derrocado el sistema constitucional, hasta el restablecimiento del mismo en 1820. Entonces fue nuevamente elegido diputado a Cortes y se trasladó a Madrid para desempeñar su cargo. Pero al comenzar el siguiente año de 1821 le sorprendió la muerte, a los sesenta años de edad (De Cueto, 1953, III: 601).

Las inquietudes de este gaditano no conocen límite: marino de profesión, se interesa por la Edad Media, el Renacimiento, el Humanismo ${ }^{15}$ y la historia en general; lo que le llevó a componer biografías y crónicas de historia local. Dicho interés atiende, en consonancia con las ideas ilustradas, a un objetivo práctico, pues sólo una perspectiva amplia es capaz de proporcionar las claves que expliquen el momento contemporáneo. Cultivó asimismo disciplinas tan dispares como la historia del arte, la descripción geográfica, la cartografía náutica, la historia de la marina, la astronomía ${ }^{16}$ o los estudios de lingüística, defendiendo activamente la pureza de la lengua ${ }^{17}$ y realizando alguna traducción de obras extranjeras (como la Electra de Crebillon, entre otras). Y todo ello sin descuidar su dilatada colaboración con la Real Academia de la Historia, que llegó a dirigir, y su intenso activismo político, social y cultural (frecuentó, por ejemplo, la tertulia de la condesa de Montijo, donde pudo conocer a importantes personalidades de la época). Colaboró con Jovellanos en la reforma de la enseñanza pública e intervino en las reformas educativas de distintos gobiernos (incluido el famoso Informe Quintana; cf. Espigado, 1999), nota esta también característica del discurso ilustrado. Con todo, nunca fue tomado muy en serio por sus contemporáneos ${ }^{18}$ y estuvo envuelto en frecuentes disputas y polémicas.

La obra literaria de este polígrafo es ingente $y$, en buena parte, permanece inédita ${ }^{19}$. Si bien su producción erudita en prosa y sus cartas poseen una importancia mucho mayor que la de su obra poética (en la que no faltan algunas crea-

\footnotetext{
15 Con respecto a este último aspecto, véase el trabajo de Ramos Santana (2002).

16 Cf. González GonzÁlez (1999).

17 Llegó a escribir una Declamación contra los abusos introducidos en el castellano. Véase al respecto García Martín (1999).

18 Véase Durán \& Romero (1999: 9): «su energía, su generosidad y ambición intelectuales solo son parangonables a su falta de realismo, que hacía que no se diese cuenta de lo inviable de muchos de sus proyectos». La variedad de contribuciones del volumen colectivo que editan estos autores da buena muestra del espíritu inquieto de Vargas.

19 Véase en Durán (1997) una catalogación y clasificación de su obra.
} 
ciones teatrales ${ }^{20}$ o variaciones del tema anacreóntico ${ }^{21}$ ), para J. L. Alborg una sola composición justifica su recuerdo: Proclama de un solterón a las que aspiren a su mano, "graciosa sátira en octavas, innegablemente regocijadas, que, si no puede calificarse en sentido estricto de poética, rebosa ingenio, acierto descriptivo y fuerza cómica» (Alborg, 1972: 434). Juicio similar es el de Bravo (1999: 170), para quien, aunque la mayoría de sus versos no escapen del prosaísmo que empaña la poesía de la época, la «ironía festiva» y el «ingenio burlón» resultan las notas más características del estilo del autor, y las encargadas de restarle inconsistencia.

En la Proclama de un solterón, además, los ecos clásicos son indudables. La sátira VI de Juvenal, a la que sigue de cerca — que la tenía en la cabeza cuando compuso la suya lo demuestra el hecho de que el propio Vargas anotó su composición, a modo de exégesis erudita, con varios versos del latino que le sirven de autoridad en su argumentación-, es una larga composición en la que se suceden los ejemplos de mujeres indeseables para los que van a casarse y, como en el caso de la de Vargas, posee un acusado carácter misógino ${ }^{22}$, si bien más extremado: para Juvenal ninguna mujer está libre de defectos y todas engañan, tiranizan, desprecian, ignoran e incluso asesinan a sus maridos.

Frente a la composición de Juvenal en la que el poeta se dirige a un hipotético interlocutor, en la Proclama es el propio solterón quien toma la palabra y se dirige a un auditorio femenino de posibles candidatas:

Frescas viuditas, cándidas doncellas, / al veneno del amor busco triaca. [...] Niñas, ojo avizor; hoy me remato. / ¿Cuál es la que echa el cascabel al gato? (estr. 1, vv. 1-2; 7-8),

a las que interpela en varias ocasiones («¿Están ustedes muchas? ¡Jesús, cuántas!» [estr. 2, v. 1]; «Oigan en rimas a la pata llana [...] el pacto marital con que me rifo»; «[...] ¿callan o callo?» [estr. 4, vv. 1-4; 8]), y les explica las virtudes

20 Cf. también Romero (1999).

${ }^{21}$ En esta línea se insertan los poemas «Dulce Meléndez Valdés», «Yo vi zagal imberbe», «Hombres sandios, ¿dó vais?». La presencia del humor en las anacreónticas, a juicio de BrAvo (1999: 178), «resta intensidad al halago sensual del vino y el amor, y podría actuar como un elemento destructor de tal modalidad poética, de los pilares sustentadores de los poemas que reproducen un lejano y aproximado eco de Anacreonte. [...] No sabemos si la intención de nuestro poeta pudo ser el ataque burlón al género, pero consideramos que el tono festivo del que lo dota puede distraer y amortiguar su esencialidad misma».

22 Con todo, Bravo (1999: 173) duda de la verdadera intención misógina del poema: «En consecuencia, sensu contrario, no sería descartable entender tales críticas zumbonas de modo opuesto, como el anhelo de nuestro autor por desterrar de la mujer una serie de lastres que estorbaban su necesaria revalorización, propia del Siglo Ilustrado». Ésta es también la opinión de MARTínez (2005), quien ofrece un completo e interesante análisis de esta composición, en paralelo a su modelo latino. 
que busca en la que haya de ser su esposa, así como los defectos de los que huye. Pero, a pesar de que la estructura y el estilo de la composición poco tienen que ver con el de la sátira latina, temática y contenidos, motivos, tópicos e incluso pasajes concretos siguen con fidelidad a su predecesor latino.

Así, por ejemplo, Vargas reivindica: «No espere que yo sufra en su embarazo / de antojos la estúpida cadena» (estr. 17, vv. 1-2), y se apoya para ello en el magisterio de Juvenal contra el despilfarro femenino, citando el v. 152 de esta sátira: quodque domi non est, et habet uicinus, ematur («Cómprese, además, lo que en casa no está y el vecino pose $\left.{ }^{23} »\right)$, a lo que Vargas comenta en nota:

Con todo, no lo aplica a los antojos, que sin duda son de uso gótico, que cuesta bochornos a un buen marido, pero de que sale sin ejemplar libre su bolsa ${ }^{24}$.

La crítica al derroche se repite más allá: «locuras con locuras eslabona / derrochando sin término ni cuenta, / y porque trajo seis gasta sesenta» (estr. 19, vv. 6-8), atendiendo nuevamente a Juvenal:

Prodiga non sentit pereuntem foemina censum; non umquam reputant quanti sibi gaudia constent (vv. 361 y 364) («La mujer es pródiga y no ve cómo se le agota el capital»; «Jamás echa cuentas de lo que le cuestan sus placeres»).

Como la mujer manirrota, la mujer masculina también será objeto de mordaz sátira por parte de Vargas ( QQue no hay manjar que cause más empacho / que mujer transformada en marimacho», dirá avanzado el poema [estr. 34, vv. 7-8 $]^{25}$ ). Y lo mismo cabe decir de la chismosa e intrigante:

Lejos de mí la dueña publicista, / hecha edecán con faldas del dios Marte, / que de Alejandro explica la conquista, / marchas, vados, botín, parte por parte; / no pierde simulacro ni revista; / en batalla campal con Bonaparte, / sueña que de un revés le deja cojo, / y del golpe al marido vacía un ojo (estr. 27).

23 Desde el verso 150 Juvenal dedica una larga tirada al reproche este vicio. Las traducciones pertenecen a la edición de M. Balasch, Madrid, Gredos, 1991. Véase un pormenorizado análisis de la sátira en cuestión en Cortés Tovar (2005).

24 Un poco más adelante volverá a interpretar a Juvenal cuando, en relación a estr. 24, vv. 7-8 («Como antaño Leonor la mojigata, / que jugó su berlina y volvió a pata»), afirma: «Juvenal no satirizó el juego de naipes en las mujeres romanas, luego las romanas no jugaban. No jugar las mujeres habiendo barajas es cosa imposible, luego no había barajas en tiempos de Juvenal».

25 Y comentará al respecto: «Por eso hay nada menos que una obra latina, que cuelgan a Valente Acidalio, consagrada a demostrar esta recóndita verdad: mulieres non esse homines». 
Para la que trae a colación los siguientes versos:

Haec eadem nouit, quid toto fiat in orbe, / quid Seres, quid Thraces agunt (vv. 401-402) («Esta mujer sabe lo que sucede en todo el mundo, lo que hacen los seres y los tracios...»).

O de la marisabidilla y la pedante:

¿Dómine por mujer? ¿Purista? ¡Cuerno! / ¡Qué tilde escapa de sus uñas horro! / ¡Armar un zipizape sempiterno / porque en lugar de gorra dije gorro! / O bien porque escribí $\sin h$ ibierno / verme tratar de bárbaro y de porro, / y dar la casa y la quietud al diablo, / ¿por qué? ¡Crimen atroz! ¡Por un vocablo! (estr. 32).

Cuyo precedente en la sátira de Juvenal es fácil de determinar:

[...] odi / hanc ego quae repetit, uoluitque Palaemonis artem / seruata semper lege et ratione loquendi, / ignotosque mihi tenet aut quarta uersus, nec curanda uiris opide castigat amicae / uerba. solecismum liceat dicisse maritum (vv. 451 y sigs.) («Odio a la mujer que repite y da vueltas a la Gramática de Palemón sin infringir nunca las leyes y las reglas de la lengua, que, chiflada por lo antiguo, me repite versos que desconozco y reprende a su amiga analfabeta por palabras que no preocupan a los hombres. ¡Séale permitido al marido cometer un solecismo!»).

$\mathrm{Y}$ al igual que Juvenal criticaba a la dama que pretende que todo lo procedente de Grecia es digno de imitación:

¿Pues hay algo de peor gusto que no hay mujer que se juzgue hermosa si de toscana no se nos hace una grieguilla, y una ateniense de pura cepa la que nació en Sulmona? No hablan más que griego, cuando a nuestras mujeres debería afrentarlas no saber latín. En griego expresan sus temores, sus iras, sus gozos y sus preocupaciones, en griego derraman los secretos de su alma. ¿¿Algo más? Sí: hacen el amor en griego,

Vargas reprocha el esnobismo francófilo de su época:

No en mis días sufrir la extravagancia / de que falsa española se me engringue; / que hasta el pan y el turrón quiera de Francia; / que con París me muela y me jeringue, / y a flaca bolsa chupe la sustancia / el modisto francés monsieur La-Pringue. / Seda de Murcia, paño de Segovia, / mantel gallego... ¿ ¿No? Pues vade, novia (estr. 20). 
La invectiva contra la superstición («La que oye brujas, duende la desvela / y ve en cada esquinazo la fantasma» [estr. 10, vv. 1-2]) y a la falsa religiosidad, con que Vargas salpica su poema en varios tramos («La que reza en latín sin saber ni jota» [estr. 39, v. 7]; «Y mientras males al marido miente, / reprueba el guiso, riñe a la criada, / y ensarta avemarías juntamente, / todo al compás de grave cabezada» [estr. 18, vv. 3-6]), es un rasgo característico del racionalismo de la época, aunque se corresponde a la perfección con el ataque que Juvenal dedica a la mujer necesitada de prácticas supersticiosas (véanse los vv. 510 y ss.).

Con todos estos inconvenientes, el poeta se ve forzado a afirmar: «Confieso, porque el diablo no me lleve, / que es un ángel mujer que sale buena» (estr. 42, vv. 5-6), dando así la réplica a la frase popularizada por Juvenal rara auis in terra, nigroque simillima cygno («ave rara en esta tierra, muy semejante a un cisne negro»), que en realidad él había tomado de Persio (I 46).

Sin embargo, a pesar de todo lo dicho, sorprende que Vargas critique en su poema el vicio de las citas clásicas, al menos en las mujeres, sobre todo por no tratarse de un despunte ocasional ${ }^{26}$ :

Tampoco sabihonda: ¡Dios me guarde! / Asco de la mujer sobre un in-folio. / La que a Plauto comenta y hace alarde / de ilustrar a Terencio en un escolio: / la que cita a Nasón mañana y tarde, / apostillando a Grevio y a Nizolio, / vaya, si gusta, con Ovidio al Ponto / y busque entre los getas algún tonto (estr. 31).

Después de sus desmanes y sus exigencias, como era de esperar, el poeta se queda sin quien lo pretenda; pero se resigna, pues prefiere la soledad a una mujer horrenda.

Vistos estos exponentes, poco más puede decirse acerca de otro autor con menor relevancia aún en su época, que se sirve del acervo cultural grecolatino con los mismos intereses, pero con menor ingenio e inspiración poética: José M. ${ }^{a}$ Vaca de Guzmán y Manrique.

${ }^{26}$ Lo mismo hace en un periódico local: «[...] en fin los aprobantes, que convirtiéndose de censores en panegyrustas, daban a los libros más despreciables los más sublimes elogios, formando unas oraciones bien prolijas, rellenas de textos de escritura con exposiciones de Alapide y Sylveira, de apotegmas de Plutarco, sentencias de Séneca, fragmentos de Plinio, y autoridades de Casiodoro, con el remate del omne tulit punctum de Horacio, y otras zarandajas [...]» (213, Academia de Ociosos, IV, 12-I-1764, pág. 213; ápud Bravo Liñán, 1999: 172, n. 10). Podría, con todo, tratarse simplemente de una crítica a la cita improcedente. 
Ponemos fin a este repaso por algunos poetas líricos con Vaca de Guzmán, cuyo recuerdo parece justificado fundamentalmente por haber derrotado a ambos Moratines en dos concursos de la Academia, con sendos poemas épicos de extensión considerable: Las naves de Cortés y Granada rendida ${ }^{27}$. En la decisión, con todo, es bien posible que influyeran motivaciones ideológicas al margen de las puramente estéticas (cf. Carnero, 1995: 604). Y es que este autor solía escribir movido por estímulos oficiales, por lo que Alborg (1972: 431) no duda en calificarlo de «poeta de concurso». Un buen ejemplo de ello lo encontramos en la composición «Las coronas del tiempo», oda compuesta por encargo para la Real Sociedad de Amigos del País de Granada, «para que se leyese el día 20 de enero de 1788, con motivo de la distribución de premios respectivos a las tres nobles artes, pintura, escultura y arquitectura, y a la del grabado». Cada una de las obras premiadas encuentra en él alusión. Así, el primer premio de pintura, descrito en nota al pie $^{28}$, es puesto en versos del modo siguiente:

De ciprés el otoño, / de acónitos, adelfas / y de mortal beleño / compone y entreteje la primera; / y los mejores rasgos / galardona con ella / que al triunvir del Oriente en la acción más piadosa manifiestan (estrs. 5-6).

Nuevamente reproducimos la noticia biográfica que ofrece De Cueto:

Doctor en ambos Derechos, del gremio y claustro de la Universidad de Alcalá, colegial por derecho de familia, llegó a ser rector perpetuo del colegio de Santiago de los Caballeros Manriques de Alcalá. Su mayor título de gloria es el canto épico titulado Las naves de Cortés destruidas. Fue premiado este canto por la Academia Española, en la junta que celebró el 13 de agosto de 1778. Su incontestable mérito le granjeó el aplauso de nacionales y extranjeros. El Journal de la Littérature tributó grandes alabanzas a esta obra poética, que fue traducida en francés por monsieur Mollien, abogado del Parlamento de París. [...]

En 1798 imprimió Vaca de Guzmán sus Obras en tres tomos, dedicándolas a la reina doña Luisa de Borbón. Contiene esta edición, entre otras muchas poesías, el romance endecasílabo Granada rendida, premiado también por la Academia Española en 1779, y el Columbano, égloga que alcanzó cierta fama y fue impresa con el pseudónimo de don Miguel Cobo Mogollón, en 1748.

27 Ambos textos pueden encontrarse digitalizados en <www.cervantesvirtual.com>.

28 «Encuentra Marco Antonio el cadáver de Bruto en el campo de batalla, desnudo por la codicia de los soldados, y lo cubre con su preciosa cota de armas. Al óleo, en un lienzo de cinco pies de alto y tres de ancho.» 
Encubierto con este mismo pseudónimo publicó tres cartas literarias, y con el de don José Rodríguez Cerezo otra carta contra algunos «que habían intentado desacreditar sus poesías». [...]

Son muy escasas nuestras noticias acerca de la vida de Vaca de Guzmán. Puede inferirse de sus propios versos que estudió en Alcalá de Henares, y pasó de allí a Andalucía con un cargo en la magistratura. [...] También puede creerse que fue natural de Sevilla y que pasó allí una parte de su juventud ${ }^{29}$ [...]. En 1789 era del Consejo de su Majestad y Ministro del Crimen de la Real Audiencia de Cataluña (De Cueto, 1952, I: 277).

Vaca de Guzmán es un poeta de profunda erudición, en cuyos poemas refleja sus amplios saberes mitológicos; pero, a pesar de ello —o quizá precisamente por ello_-, sus composiciones resultan frías y académicas en exceso, y carecen de la gracia o el ingenio que veíamos en los autores anteriores.

Así, el romance endecasílabo Granada rendida, al que ya hemos hecho referencia, comienza en tono heroico, remedando las grandes epopeyas, con la preceptiva invocación a la Musa:

Desciende en mi favor del alto cielo, / tú, que demuestras en el vate argivo / el verso digno de cantar las guerras / y hazañas de monarcas y caudillos, / y dime joh musa!, cómo conquistaron, / siendo su tutelar el cielo mismo, / los Católicos Reyes el emporio / en donde muere el Darro cristalino (vv. 1-8).

De acuerdo con el género practicado, el recurso poético más empleado es el símil, que puede llegar a alcanzar gran complejidad, como se demuestra en el siguiente caso, alambicada presentación de la aurora:

Desaparece, y de Titón la esposa / apenas el ejército lucido / de las estrellas ahuyentaba, cuando / así dio a su razón principio (estr. 76).

O este otro, en el que el colorido de Granada que se presenta ante Villena a su llegada es comparado con la diosa Iris, personificación del arco que lleva su nombre:

Imitando de la hija de Taumantes, / opuesta al sol, mil varios coloridos, / su suelo esmaltan la morada viola, el clavel rojo y los azules lirios (estr. 57).

${ }^{29}$ Reyes (2006 ${ }^{4}$ : 193) da por cierto su nacimiento en Sevilla (Marchena), en el año 1744. 
Sólo en las dos estrofas siguientes Febo se emplea en lugar de la denominación más vulgar del astro celeste y las aves no son tales, sino los personajes que en ellos se metamorfosearon:

En los álamos verdes Filomena / suelta la voz con delicados trinos, / Itis la escucha, y lloran igualmente / de Progne y de Tereo los delitos (estr. 59) ${ }^{30}$.

Basten estos versos para dar idea del tono y los recursos de un poema en el que el tema histórico no justificaría, en principio, tal profusión de alusiones mitológicas.

En otras ocasiones, la referencia clásica no es tan transparente, pero parece que el autor tiene siempre en la cabeza tal fuente de inspiración y se esfuerza por demostrarla. En los siguientes versos de «Llanto de Granada», elegía compuesta con motivo de la muerte del rey Carlos III,

Sitios alegres de verdor ameno, / donde las almas, se creyó algún día / de sus ligeros crímenes purgadas, / gozar interminables las delicias (estr. 2),

pocos indicios hacen pensar en que el autor, según él mismo explica, se refiere al hecho de que «es opinión que los antiguos colocaban en la vega de Granada los Campos Elísios».

Las resonancias del comienzo de la Eneida, al igual que en casos anteriores, son patentes también en poemas como La felicidad, "poema enviado a la Real Sociedad de Amigos del País de la ciudad de Granada», en cuyo comienzo hace referencia al romance recién mencionado, para abordar un tema alejado del que cantó entonces:

Yo aquel que en otro tiempo, los triunfantes / Católicos Monarcas celebrando, / canté los destrozados eslabones / de Agar en la metrópoli del austro; / de aquellos padres de la patria ahora / al más ínclito nieto derivado, / el mismo influjo en el emporio mismo, / feliz admiro y obediente canto. / Aparta, heroica musa, de mi oído / el marcial eco que aún parece alcanzo / del ronco parche, y el metal horrendo / cuyos rumores trasladaste al labio (estrs. 1-3).

Nuevamente aquí, la cita erudita se banaliza como elemento embellecedor y ennoblecedor, al ser considerado como un mecanismo compositivo en sí

30 El mito de Filomela es también motivo para la composición de una serie de «cantilenas» que llevan ese nombre. Sobre las recreaciones del mito en la literatura española, véase el completo estudio que le dedica Martín Rodríguez (2008). 
mismo. Hasta tal punto, que una ristra de nombres sirven para construir una estrofa:

La fama entonces separó, imperiosa, / a Apeles, Nicias, Zeuxis y Parrasio, / a Dinócrates, Dédalo y Vitruvio, / a Fidias, Praxíteles y Agesandro (estr. 9).

Y con un barroquismo más acusado, plasmado en el empleo del hipérbaton y de un léxico menos accesible, no desaprovecha la oportunidad de incorporar incluso cultismos tomados directamente del griego:

Tisbe amorosa, en árbol convertida, / pábulo apronte al hilador gusano, / que esas mismas abejas que os retratan / su bombo enseñarán al reptil bando (estr. 76).

Lo que le obliga al empleo de notas explicativas:

Es voz griega; significa el zumbido de las abejas, y por ser parecido al murmurio que forman, al comer la hoja, los gusanos de seda, se dio a estos el nombre de bombyces. Así lo sienta, entre otros, el erudito Francisco Cascales en sus Cartas filológicas.

El tono grave y el culturalismo extremado empañan incluso sus composiciones menores de asunto frívolo, carentes del gracejo que alcanzan los autores estudiados previamente. Lo vemos en el romance menor que desarrolla el tema «Pidiendo unas plantas de frutales de la huerta de la Esgaravita de Alcalá de Henares a su dueño», y que comienza así:

Lleguéme a tu huerta un día / de los pocos que madrugo, / oh tú, la más generosa / hespérida de Cómpluto (vv. 1-4).

Pero el conocimiento de lo clásico no termina en las referencias mitológicas y el autor se emplea a fondo en la pureza de otros aspectos, como puede ser el género (pueden mencionarse, por ejemplo, las églogas «Columbano» y «Delfino», compuestas con apego a los modelos clásicos), o la métrica. La oda «A la muerte de don José Cadalso» se compone con una firme voluntad de ajustarse al metro escogido ${ }^{31}$,

31 Sobre ella, informa prolijamente el autor: «Forman esta oda versos castellanos de artificio latino. Son unos sáficos, si no común composición de nuestros poetas, no desconocida de ellos, pero con la novedad del adorno de la asonancia, medio generalmente preferible a mi oído entre la vehemencia de la consonancia y la disonancia de la soltura, lo cual si por muchos ha sido desechada en nuestros metros originarios y en los oriundos de Italia, de todos cuantos he visto o han llegado a mi noticia, ha sido adoptada en los sáficos en donde la 
con lo que, una vez más, se entronca con la herencia clásica a través de la propia tradición literaria.

Ahora bien, además de los mencionados poemas y otros más para conmemoración de distintas sociedades y acontecimientos políticos, compuso una larga obra, de título Himnodias ofastos del Cristianismo, con la que se proponía realizar una breve biografía del santo de cada día, pero que dejó inacabada (su calendario se detuvo el 31 de marzo). En ellos, como es evidente, y aun teniendo en cuenta el referente de los Fastos ovidianos, la alusión a la mitología grecolatina, en tanto que pagana y alejada de las intenciones moralizantes y aleccionadoras del autor $^{32}$, se limita de manera notoria, si bien las referencias fruto de sus extensos conocimientos del mundo clásico reaparecen casi de manera inevitable:

Grecia, que siete sabios / levantas a los cielos, / e intentas de su fama / llenar al universo (Día 4 de enero, San Aquilino y compañeros mártires; estr. 1).

Aunque sólo sea para recomendarle que olvide la grandeza de esos personajes, en beneficio de otros tantos surgidos en el seno de la Iglesia.

\section{A modo de conclusión}

Después de este repaso por la obra poética de tres autores del siglo XVIII sin demasiada relevancia ni reconocimiento, se puede concluir que, en ellas, el elemento de la cultura clásica aparece motivado con fuerza por cuestiones que escapan a los criterios meramente artísticos o estilísticos y lindan con otros más bien ideológicos y elitistas. Ya hemos dicho que, en contra de lo que pudiera parecer si tenemos en cuenta la activa política educativa de distintos gobiernos ilustrados, la cultura era en esta época patrimonio de unos pocos y, en ese marco, la instrucción en la Antigüedad grecolatina era considerada un medio imprescindible para aproximarse a la alta cultura escrita — con la misma importancia que el conocimiento de las principales lenguas europeas-. Y ello coin-

consideración a su origen nos representa menos necesidad de asonancia o consonancia, y viene a ser el oído esclavo de la reflexión. No son versos sáficos todos los bautizados con este nombre; porque creen muchos, y creen mal, que lo son todos los endecasílabos; necesitan para serlo la buena disposición de los tiempos de la pronunciación, combinando la naturaleza de los acentos con la exigencia del contexto. He procurado cumplir con esta regla, cuya trasgresión es perceptible, no solo al que entienda su economía y sepa explicarla con términos poéticos, según los principios, sino al que tenga un oído medianamente arreglado, que seguramente distinguirá en el sáfico un sonido del que carecen muchos, aunque no todos los endecasílabos castellanos».

${ }^{32}$ Véase el prólogo a la edición de 1792, reproducido en DE CuETo (1953, III: 318-319). 
cide con un momento en el que se está produciendo lo que S. Settis (2006: 85) denomina el «divorcio entre anticuaria y práctica artística», y en el que Europa se encuentra conformando un concepto de lo clásico «tomando de la Antigüedad griega y romana tanto el término como el impulso de construir modelos normativos para el presente», a pesar de que lo clásico podía ser aplicado también a manifestaciones más recientes y pertenecientes a cada una de las culturas nacionales, tal y como hemos visto que ocurrió en el Neoclasicismo español. Sin embargo, según concluye Settis su argumentación,

Cuando la categoría de lo «clásico» se fijó con claridad, para convertir la Antigüedad «clásica» (es decir, grecorromana) en un campo de estudios bien definido, fue porque esa delimitación de campo y la noble y atrayente palabra con la que se describía en las universidades, en los institutos y en los curricula, sirvió para elevar la educación clásica a la cima de los sistemas educativos, fabricando con ella un código cultural en el que se reconociesen mutuamente las élites de distintas lenguas, naciones y países (Settis, 2006: 88).

De hecho, es precisamente en esta época cuando comienza a gestarse el contenido semántico moderno del adjetivo clásico aplicado a las lenguas, las culturas y las literaturas de la Antigüedad grecolatina. El ámbito propio del término latino classis no era el artístico ni el literario, sino el socioeconómico. El classicus por antonomasia era un miembro de la clase más elevada y, por tanto, el mejor contribuyente a las arcas del Estado. Según ha estudiado García Jurado (2007: 169-175), junto a la deferente denominación de lengua sabia, el siglo XVIII vio nacer el apelativo ilustrado autores clásicos $^{33}$, en principio con el sentido de «autores serios» y opuesto, por tanto a «autores ligeros», pero pronto usado en referencia casi exclusiva a los autores griegos y latinos ${ }^{34}$. Sin embargo, como hemos tratado de mostrar, tanto el adjetivo en su nueva aplicación como la repercusión elitista que se concedía al legado clásico en general estaban en este momento más apegados a su origen etimológico de lo que cualquier conciencia filológica de la época pudiera vislumbrar.

33 Denominación que, como se encarga de subrayar el propio García Jurado (2007: 170-171 y n. 17), fue aplicada ya al terreno literario, en referencia fundamental a la corrección lingüística, por Aulo Gelio.

34 «Ya no se trata de que entre los autores considerados clásicos destaquen los grecolatinos, sino que la condición de ser grecolatinos, como tal grupo, los convierte en clásicos» (GARCía JuRAdo, 2007: 173), lo que justifica, dicho sea de paso, que cualquier escritor de esas lenguas pasara a ser miembro de un canon selecto, aunque literariamente no lo mereciera. Al éxito de la denominación contribuyó el empleo en relación con su orientación escolar, al ser autores que se estudiaban «en clase» (cf. ibídem). 
Referencias

Alborg, J. L. (1972), Historia de la literatura española. Siglo XVIII, Madrid, Gredos.

Bravo Liñán, F., «Anotaciones a la poesía de Vargas Ponce», en Durán \& Romero (eds.), pp. 169-179.

Carnero, G. (coord.) (1995), Historia de la literatura española. Siglo XVIII (2 vols.), Madrid, Espasa Calpe.

Cortés Tovar, R. (2005), «Indignación satírica contra las mujeres romanas y sus pasiones: la misoginia en Juvenal», en A. Pedregal Martín \& M. González González (eds.), Venus sin espejo. Imágenes de mujeres en la Antigüedad clásica y el cristianismo primitivo, KRK Ediciones, Oviedo, pp. 139-159.

Cueto, L. A. DE (1952-1953), Poetas líricos españoles (3 vols.), Biblioteca de autores españoles. Desde la formación del lenguaje hasta nuestros días, Madrid, Atlas.

Durán López, F. (1997), José Vargas Ponce (1760-1821). Ensayo de una bibliografía y crítica de sus obras, Cádiz, Servicio de Publicaciones de la Universidad de Cádiz.

— \& Alberto Romero Ferrer (eds.) (1999), «Había bajado de Saturno». Diez calas en la obra de José Vargas Ponce, seguidas de un opúsculo inédito del mismo autor, Cádiz, Servicio de Publicaciones de la Universidad de CádizInstituto Feijoo de Estudios del Siglo XVIII de la Universidad de Oviedo.

Espigado Tocino, G., «El pensamiento pedagógico de José Vargas Ponce», en Durán \& Romero (eds.), pp. 133-167.

Fortuño, S. (1997), Conde de Noroña, Antología poética, Madrid, Cátedra.

- (2003), Conde de Noroña, Poesías asiáticas, Madrid, Hiperión.

García Jurado, F. «¿Por qué surgió la juntura "Tradición Clásica"? Razones historiográficas para un concepto moderno», Cuadernos de Filología Clásica (Estudios Latinos) 27 (2007), pp. 161-192.

García Martín, J. M. ${ }^{a}$, «La Declamación contra los abusos introducidos en el castellano, de José Vargas Ponce», en Durán \& Romero (eds.), pp. 99-105.

González González, F. J., «Don José de Vargas Ponce, la astronomía, la cartografía náutica y la historia de la marina», en Durán \& Romero (eds.), pp. 199-209.

González Palencia, A. (1931), «Don José María Vaca de Guzmán, el primer poeta premiado por la Academia Española», Boletín de la Real Academia Española 18, pp. 293-347.

Martín Rodríguez, A. M. ${ }^{a}$ (2008), El mito de Filomela en la literatura española, León, Universidad de León. Área de Publicaciones. 
Martínez Sariego, M. M. a (2005), «Adiós amigas, próspero viaje. Ecos misóginos de la Sátira VI de Juvenal en la Proclama de un solterón de Vargas Ponce», en J. F. González Castro et al. (eds.), Actas del XI Congreso Español de Estudios Clásicos (Santiago de Compostela, 15-20 de septiembre de 2003), Madrid, SEEC, pp. 753-762.

Picón García, V. (2005), «El tópico del Beatus ille de Horacio y las imitaciones del Marqués de Santillana, Garcilaso y Fray Luis de León», Edad de Oro 24, pp. 259-285.

Polt, J. H. R. (1975), Poesía del siglo XVIII, Madrid, Castalia.

Ramos Santana, M. ${ }^{a}$ C. (2002), «La recepción del Humanismo en la obra del ilustrado José Vargas Ponce», en J. M. ${ }^{a}$ Maestre Maestre, J. Pascual Barea, L. Charlo Brea (eds.), Humanismo y pervivencia del mundo clásico. Homenaje al profesor Antonio Fontán, III.5, Instituto de Estudios HumanísticosLaberinto-CSIC, Alcañiz-Madrid, pp. 2249-2256.

Reyes, R. $\left(2006^{4}\right)$, Poesía española del siglo XVIII, Madrid, Cátedra.

Romero Ferrer, A. «Vargas Ponce en el teatro: de la reforma de la Ilustración a la polémica calderoniana», en Durán \& Romero (eds.), pp. 107-132.

SetTis, S. (2006), El futuro de lo clásico, Madrid, Abada. 